\title{
Design and Evaluation of a Gamified e-Learning System for Statistics Learning Activities
}

\author{
Marcos Mincov Tenório ${ }^{1}$, Rui Pedro Lopes ${ }^{2}$, Lourival A. Góis ${ }^{1}$, Guataçara dos Santos Junior ${ }^{1}$ \\ ${ }^{1}$ Federal University of Technology - Paraná, Brazil \\ ${ }^{2}$ Polytechnic Institute of Bragança, Portugal
}

\begin{abstract}
Researchers in statistics learning have made an effort to develop technological solutions to support students in this field. However, such solutions must involve and engage students to perform learning activities to develop their statistical thinking. In this scenario, this study proposes the design of a gamified e-learning system to involve students when they perform learning activities. We analyze students' behavior towards statistics activities when using the environment. To achieve these goals, this project focuses on a gamified structure for the development of learning activities with a reward system. The learning activities are based on question and answers developed by teachers to measure the students' understanding of different course contents and also provide them with a problem-based approach. The project was applied in a Probability and Statistics course during 30 days. The results suggest a positive outcome mostly because the designed gamification elements achieved their desired role inside the environment.
\end{abstract}

\section{Introduction}

In past years, educational researchers suggested different approaches to the traditional educational method, in which the center of the entire educational process relied on the content and teachers. Nowadays, new approaches suggest using resources and tools to allow students to be the center of their own knowledge construction, creating a studentcentered or constructivist approach [1].

This constructivist approach leads to different educational initiatives regarding the usage of new technologies and new methods to improve learning. Nowadays, with Internet popularity and the spreading of new devices, such as computers, tablets and smartphones, e-learning environments has become essential tools for these new educational methods [2].

In an e-learning context, students are active participants and play a center role in their own learning process using available tools to construct their knowledge. In addition, e-learning systems enable new possibilities for the insertion of methods that could improve the learning process and engage students in different tasks [3].
Gamification [4] emerges in this scenario as one of these new techniques that can be used inside elearning systems [5]. Such technique offers a creative alternative to transform learning environments into a more efficient, involving and engaging process. A gamified scenario may offer freedom, feedback, progressions, rewards, context, narratives, among others. Consequently, game-based approaches may promote several advances in educational contexts [5].

Given this context, this study suggests the insertion of gamification concepts in an e-learning environment, creating a new artefact that aims at the students' involvement when they perform learning activities and, therefore, helping teachers on their daily practices (summative assessments [6]).

To evaluate this educational product, we designed a case-study and selected the Probability and Statistics field. We believe this subject is fundamental to several knowledge fields, considering the difficulties students face regarding their teaching and learning process [7]. We collected data from the e-learning usage of volunteer students of Probability and Statistics class, which allows the understanding of the effects this e-learning system may have on the discipline course.

This study is organized as follows: Section 'Theoretical Background' provides the theoretical foundation and background for the study regarding statistics field, ICT insertion and gamification technique. The section 'System Description' describes the e-learning system, its development and gamification insertion. Section 'Methodology' describes the methodology involved in the studycase design of this e-learning system in Probability and Statistics class. In section 'Results' we discuss the findings. Section 'Conclusions' completes this research.

\section{Theoretical Background}

\subsection{Statistics learning and ICT}

The statistics field is a fundamental tool for several areas nowadays. This idea is mostly driven by the characteristics that distinguish this science field. 
Statistics provide tools to perform inferential analysis to study and comprehend the phenomena around high amount of data and variables from different sources, creating useful knowledge to many fields [7].

Based on its importance, researchers suggest statistics field should be present in scholar curricula and mainly in our everyday practice [8]. However, although statistics learning exists in many curricula since primary school, students still demonstrate a growing inability, even on higher education, to perform statistical analysis [8].

Given this issue, educators and researchers face a challenge to advance the learning in this field. Therefore, some authors suggest combining theories, experiments and computational resources, so that many studies relating Information and Communication Technology (ICT) and statistics learning can emerge. ICT seems prominent because it offers many possibilities to explore and develop students' statistical thinking through different tools to support, explore and simulate statistics concepts and ideas [9].

E-Learning tools emerge and explore ICT advantages to foster statistics learning. An e-learning system combines ICT with educational scenarios, creating learning environments and enabling their access from anywhere, at any time through the Internet [10]. Such flexibility allows students to access resources and use these platforms [11]. However, even with a desired e-learning structure, students must also be inspired to spend more time and energy in the learning process, because of the increasing active role they must assume. The gamification technique is suggested to promote this involvement and engagement.

\subsection{Gamification in e-Learning environment}

Gamification, defined as "the use of game design elements in non-game contexts," is primarily designed to increase the involvement of users in online environments [4]. To involve and motivate users to explore some environments, gamification uses game elements associated with game mechanics. In other words, the toolbox are the elements, or game elements that can be used individually or combined to achieve a goal [4]. Then a systematic and artistic design wrap up these elements and provide a creative mechanic behind it. Lastly, this technique are applied into systems in which its purpose diverge from traditional game objectives, going beyond fun and entertainment, called non-game contexts [12].

The learning environments, especially e-Learning environments, seems to be a prominent context to a gamified approach, given that the user's involvement with such tools may promote positive outcomes with an educational perspective. However, to properly gamify an educational environment it is required to plan and develop elements that motivate and improve positive behaviors such as in [13] [14].

\section{System description}

The proposed e-learning system was developed based on the Pressman Evolutive Prototyping life cycle [15]. Given the project characteristics, was also used a specific five-phase model to develop learning environments with gamification technique [16]. A web-based platform was selected to allow interoperability to several hardware platforms and used HTML, PHP, JQuery and CSS languages. The MySQL database management system was used due to the interoperability with the programming languages. Finally, the interface patterns were based on Nielsen Usability Heuristics [17].

\subsection{Software description}

The developed system is called eClass and offers three main modules: Content Management; Learning Activities; Assessments. In the Content Management module, students access and download regular course content uploaded by teachers, such as class notes, lesson plans, study guides, textbooks, and other relevant materials.

In the Learning Activities module, teachers upload questions into the database, and students perform the learning activities (or activity tests). To perform an activity test, students select the desired content and difficulty parameters, then a set of questions randomly selected from the system's database become available (Figure 1). Unlimited attempts are possible, allowing students to perform several learning activities with the same parameters. This approach creates a sandbox-style game, meaning there is no linear narrative structure that guides the students [18], only the gamification elements defined in the next subsection. When students finish an activity test, instant feedback is offered with their activity performance result (AP) and achievements.

Here, students must be oriented to perform attempts in all parameter sets available (contents and difficulties) and being constantly remembered that the objective is to achieve high AP on every activity.

The students' APs are used in the Assessments module. The teachers use such results to collect constant feedback about the students' progressions and difficulties. Teachers may act upon these results and perform formative or summative assessments. In this sense, eClass also helps teachers suggesting the 
student's final score (FS) based on the maximum AP of each parameter set chosen. To FS calculus, first we calculate a unique content score and a weighted average based on maximum AP of each difficulty parameter. Then a simple average with all contents score values are calculated to obtain FS. By the given equation the FS value will reflect the students' performance inside the system and the system exploration.

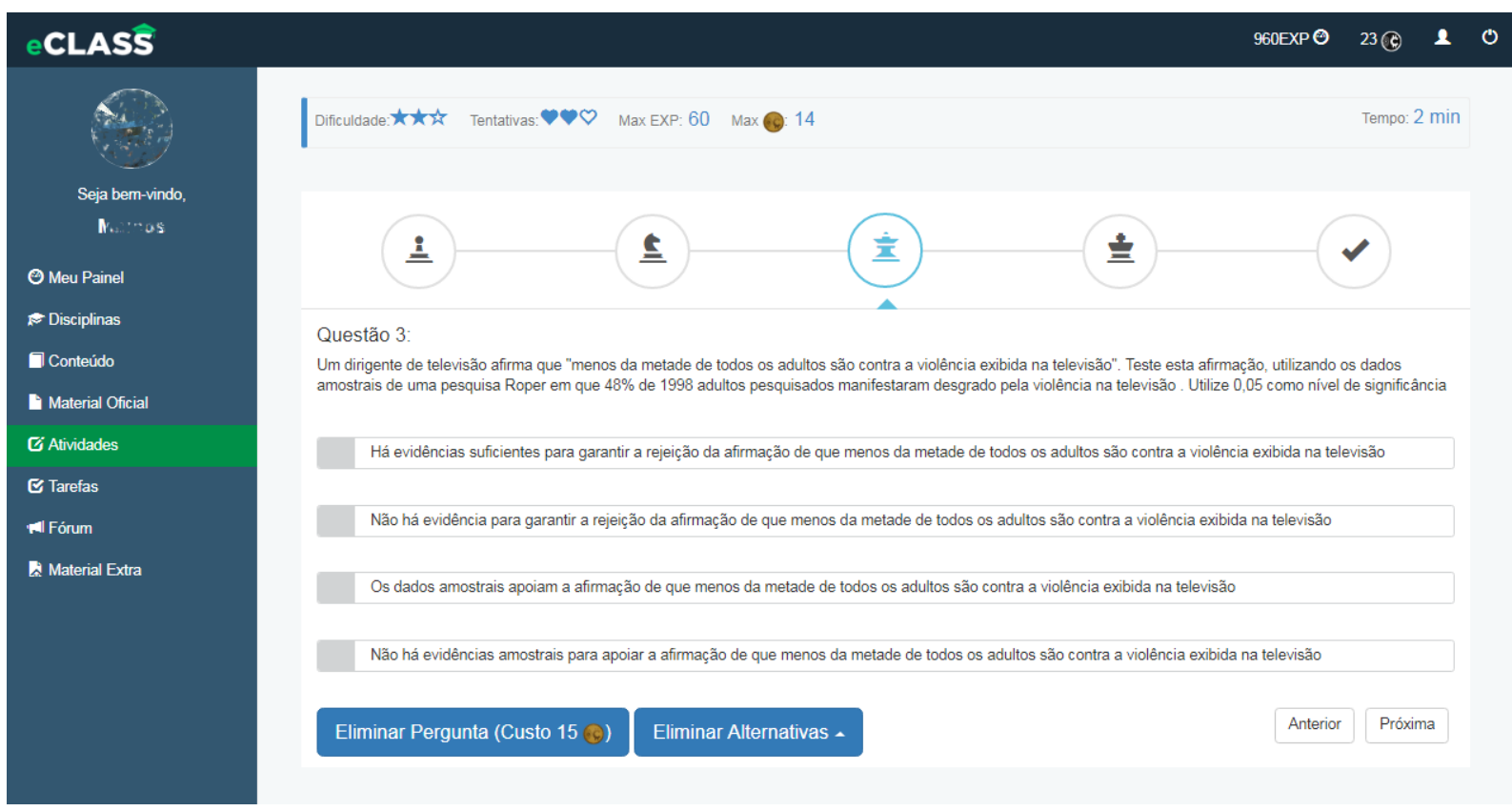

Figure 1. Teaching-learning activity screenshot

Here, the gamification technique was primarily designed to involve and engage students in learning activities, but also to guide them in a proper pedagogical sequence, instead of diverging from teachers' desired learning pathways. The designed elements and mechanics to achieve these goals are defined on the following subsection.

\subsection{Gamification elements and mechanics}

As suggested before, to properly gamify a learning environment it is imperative to never drive students away from the learning objectives [19]. In such cases, a gamification plan is required to choose suitable elements and mechanics to learning environments [14].

First, the element 'Points' was selected because it offers an instant feedback for students, informing the success in a task [20]. This element (here called EXP) is a numeric value that students collect during the eClass usage. The students' total EXP is calculated through Equation 1. Where: EXPi is obtained after completing an activity test; i identifies each attempt; $\mathrm{n}$ is the total number of attempts.

$\sum_{i=1}^{n} E X P_{i}$

To EXPi calculus, we consider the two activity parameters: dif, difficulty chosen; $c$, content chosen. Each activity attempt within a content and difficulty parameter $\left(c_{-} d i f_{j}\right)$ results in an EXPi value, a function of the activity performance (AP), inversely proportional to the number of attempts inside each set of parameters, given by Equation 2 .

$$
E X P_{i}=\begin{array}{lll}
A P * 1.0 & \text { if } & c_{-} d i f_{j}=1 \\
A P * 0.6 & \text { if } & c_{-} d i f_{j}=2 \\
A P * 0.3 & \text { if } & c_{-} d i f_{j}=3 \\
A P * 0.1 & \text { if } & c_{-} d i f_{j} \geq 4
\end{array}
$$

For each attempt inside a parameter set, the students' EXPi is reduced. This mechanic allows students to make unlimited attempts, as their possible reward progressively decreases. This mechanic help students avoid parameters (contents or difficulties) that they are not prepared yet because, if they choose wrong, they will miss an opportunity to achieve higher rewards in future attempts. On the other hand, it allows the system to release all activities and operate in a sandbox-style, given to students the freedom to follow their desired sequence but also guided by gamification elements.

The second element is Virtual Currency (here called eCoin). The students collect this element in a function of the earned EXPi and the difficulty chosen in an activity attempt, Equation 3. 


$$
e \text { Coin }=\left(\frac{E X P_{i}}{10}\right) \times d i f
$$

The eCoins element is a virtual good that can be traded. The trades inside the activity tests allow students to remove alternatives or an entire question from the activity test set.

These elements were built to make students follow a teacher's designed learning pathway, allowing freedom of choice but still guiding them through game elements inside the e-learning environment. The EXP and eCoins are the core gamification elements used in eClass.

However, other elements are used, such as: Progress bars, that are used to give feedbacks to students on AP result; Levels, that are used to structure contents and difficulties; Pathways, that are used to order contents by the teachers' desired pathways; Time Restriction, that are used to control time inside activities attempts; Limited resources, that are used to control the eCoins balance and possible trades. Such elements also play important roles inside the environment but with a more simplistic mechanic behind it.

\section{Methodology}

\subsection{Research design}

To analyze the impact of a gamified e-learning environment (eClass) on students' behavior towards statistics learning activities, the first stage of this research was to develop the system as previously defined on the system description. Then a case-study design was used as part of this study. We used quantitative data to measure the students' engagement and evaluate if they were guided by gamification elements to use the eClass and perform statistics learning activities.

The specific research questions evaluated were: Which effects do a gamified e-learning environment produce on learners when performing statistics learning activities?

The data were retrieved directly from the system's database trough users logs, collecting all users' actions inside the system. Then, users' actions and results collected were compared with the final discipline scores to answer the research question.

\subsection{Participants and study site}

Participants of this study took an undergraduate course at the Polytechnic Institute of Bragança (IPB) - Portugal. Subjects were enrolled in a night-time class of statistics of business management program. The students were enrolled in a post-laboral class, meaning that they work during the day and perform classes during the night. In total, 12 students participated in the study, 8 men $(66.7 \%)$ and 4 women $(33.3 \%)$.

\subsection{Study-Case Procedures}

Before the application starts, the teacher receives an initial support to use eClass and insert the contents and exercises. After this initial support, the teacher uploaded 175 exercises divided into 11 contents and 3 difficulties. The exact numbers of exercises divided by each content are presented in the Table 1.

Table 1. Contents and exercises uploaded by teacher in eClass

\begin{tabular}{l|l|c|c|c|c}
\hline \hline \multicolumn{1}{c}{ Modules } & \multicolumn{1}{c|}{ Content } & \multicolumn{3}{c}{$\begin{array}{c}\text { Number of Exercises } \\
\text { Easy - Regular - Hard }\end{array}$} & \multirow{2}{*}{ Total } \\
\hline Introduction & General Introduction & 7 & 0 & 0 & 7 \\
\hline \multirow{2}{*}{ Descriptive Statistics } & Data Classification & 2 & 2 & 0 & 4 \\
\cline { 2 - 6 } & Characterization of Sample / Population & 6 & 5 & 6 & 17 \\
\hline \multirow{2}{*}{ Probability } & Combinatory Calculus & 14 & 8 & 0 & 22 \\
\cline { 2 - 6 } & Probability & 7 & 7 & 3 & 17 \\
\hline \multirow{2}{*}{ Distributions } & Univariate Discrete & 9 & 6 & 5 & 20 \\
\cline { 2 - 6 } & Univariate Continuous & 6 & 7 & 4 & 17 \\
\hline \multirow{3}{*}{ Interval Estimation } & Populational Average & 5 & 2 & 3 & 10 \\
\cline { 2 - 6 } & Binomial Proportion & 8 & 4 & 2 & 14 \\
\cline { 2 - 6 } & Populational Variance & 14 & 17 & 11 & 5 \\
\hline Hypothesis Tests & Hypothesis Tests & 4 & 1 & 42 \\
\hline \hline
\end{tabular}

Then, students received an initial support to access the system and perform their registration. To students was also provide a digital version of the
eClass user's guide presenting the main system's functionalities and a guidance for performing activity tests. All functions were fully available for students 
to perform their actions. The students could access the system through a web-browser, but they could use any platform (from desktop computer to mobile devices) at any time.

To students the eClass system became available during 30 days and there was no intervention from researchers during this period. Students' were free to make learning activities attempts in any contents and difficulty. Although the gamification mechanics guide the students' pathway, they were free to break the regular sequence and perform more advanced learning activities as suggested on previous sections.

During this period, the teacher was able to access the students' development and receive a constant feedback on their actions and performance. The teacher may also access the students' specific answers on each activity test and providing guidance when is required. At the end, the teacher receives the student's final score (FS) to perform further evaluations.

\subsection{Data collection and analysis}

Students' involvement and engagement was measured by two components, behavioral engagement and cognitive engagement.

Behavioral engagement can be defined as the students' participation and investment in activities, measured by the frequency of the students' actions inside eClass and collected from the database logs. The behavioral variables measured were: earned EXP; earned eCoins; traded eCoins; learning activities attempts; trades performed.
Cognitive engagement relates to the attention and effort that students dedicate to the eClass system, which reflects on their score results. The cognitive variables measured were: average performance on activities (AP); student's final score (FS). Further conclusions were possible when we also collected the discipline final score and analyzed the correlations between these values.

Descriptive statistics of the collected data were used to describe the behavioral and cognitive engagement of students.

\section{Results and Discussions}

To answer the research question, we collected quantitative data and summarized these values. The following subsections present the results obtained and perform a discussion through behavioral and cognitive engagement perspectives.

\subsection{Characterization of Behavioral Engagement}

To perform this analysis, we collected the eClass' database logs and analyze two items, the 'Gamification Data' and the 'Usage Data' presented in each column of the Table 2.

On the Table 2, each line presents an individual student data retrieved from database logs and discipline score results. The values were summarized with descriptive statistics presenting the Average (AVG), Standard Deviation (STD) and Coefficient of Variation (CV).

Table 2. Data retrieved from database logs and discipline final result.

\begin{tabular}{|c|c|c|c|c|c|c|c|c|}
\hline \multirow[b]{2}{*}{$\begin{array}{l}\text { Student } \\
\text { ID }\end{array}$} & \multicolumn{3}{|c|}{ Gamification Data } & \multicolumn{2}{|c|}{ Usage Data } & \multicolumn{3}{|c|}{ Performance Data } \\
\hline & $\begin{array}{c}\text { Earned } \\
\text { EXP }\end{array}$ & $\begin{array}{l}\text { Earned } \\
\text { eCoins }\end{array}$ & $\begin{array}{l}\text { Traded } \\
\text { eCoins }\end{array}$ & $\begin{array}{l}\text { Activities } \\
\text { attempts }\end{array}$ & $\begin{array}{c}\text { Trades } \\
\text { performed }\end{array}$ & $\begin{array}{c}\text { Average } \\
\text { Score }\end{array}$ & $\begin{array}{l}\text { eClass } \\
\text { Score }\end{array}$ & $\begin{array}{c}\text { Final } \\
\text { Score }(\%)\end{array}$ \\
\hline 3 & 3888 & 522 & 480 & 314 & 67 & 79.97 & 49.91 & 60 \\
\hline 6 & 3574 & 649 & 530 & 117 & 53 & 71.11 & 94.54 & 70 \\
\hline 2 & 2688 & 475 & 22 & 93 & 4 & 62.98 & 68.78 & 50 \\
\hline 9 & 2611 & 416 & 389 & 92 & 39 & 62.84 & 60.14 & 30 \\
\hline 12 & 1421 & 174 & 45 & 36 & 6 & 63.85 & 32.56 & 30 \\
\hline 10 & 1180 & 148 & 86 & 63 & 13 & 55.27 & 30.02 & 35 \\
\hline 5 & 1083 & 142 & 68 & 43 & 10 & 53.38 & 33.52 & 65 \\
\hline 1 & 799 & 112 & 0 & 35 & 0 & 42.03 & 27.35 & 60 \\
\hline 4 & 336 & 33 & 0 & 8 & 0 & 72.20 & 14.27 & 50 \\
\hline 7 & 98 & 10 & 0 & 2 & 0 & 49.00 & 6.95 & 55 \\
\hline 8 & 0 & 0 & 0 & 0 & 0 & 0 & 0 & 15 \\
\hline 11 & 0 & 0 & 0 & 2 & 0 & 0 & 0 & 0 \\
\hline AVG & 1473,2 & 2223,42 & 135,00 & 6767,08 & $\begin{array}{ll}16,00 \\
\end{array}$ & 251,05 & 34,84 & 40,33 \\
\hline STD & 1389,4 & 229,52 & 204,15 & 87,29 & 23,49 & 26,03 & 29,07 & 21,46 \\
\hline $\mathrm{CV}$ & 0,94 & 1,03 & 1,51 & 1,30 & 1,47 & 0,51 & 0,83 & 0,50 \\
\hline
\end{tabular}


Table 3. Correlation matrix of all collected data combinations

\begin{tabular}{c|c|c|c|c|c|c|c|c}
\hline \hline & \multicolumn{3}{|c|}{ Gamification Data } & \multicolumn{2}{c|}{ Usage Data } & \multicolumn{3}{c}{ Performance Data } \\
\hline & $\begin{array}{c}\text { Earned } \\
\text { EXP }\end{array}$ & $\begin{array}{c}\text { Earned } \\
\text { eCoins }\end{array}$ & $\begin{array}{c}\text { Traded } \\
\text { eCoins }\end{array}$ & $\begin{array}{c}\text { Activities } \\
\text { attempts }\end{array}$ & $\begin{array}{c}\text { Trades } \\
\text { performed }\end{array}$ & $\begin{array}{c}\text { Average } \\
\text { Score }\end{array}$ & $\begin{array}{c}\text { eClass } \\
\text { Score }\end{array}$ & $\begin{array}{c}\text { Final } \\
\text { Score (\%) }\end{array}$ \\
\hline Earned EXP & - & 0,98 & 0,86 & 0,85 & 0,87 & $0,68 *$ & 0,91 & $0,47 * *$ \\
\hline Earned eCoins & 0,98 & - & 0,84 & 0,76 & 0,82 & $0,63 *$ & 0,96 & $0,47 * *$ \\
\hline Traded eCoins & 0,86 & 0,84 & - & 0,77 & 0,97 & $0,52 * *$ & 0,75 & $0,36 * *$ \\
\hline Activities attempts & 0,85 & 0,76 & 0,77 & - & 0,87 & $0,57 * *$ & $0,58 *$ & $0,40 * *$ \\
\hline Trades performed & 0,87 & 0,82 & 0,97 & 0,87 & - & $0,54 * *$ & $0,69 *$ & $0,37 * *$ \\
\hline Average Score & $0,68 *$ & $0,63 *$ & $0,52 * *$ & $0,57 * *$ & $0,54 * *$ & - & $0,66 *$ & 0,72 \\
\hline eClass Score & 0,91 & 0,96 & 0,75 & $0,58 *$ & $0,69 *$ & $0,66 *$ & - & $0,54 * *$ \\
\hline Final Score (\%) & $0,47 * *$ & $0,47 * *$ & $0,36 * *$ & $0,4 * *$ & $0,37 * *$ & 0,72 & $0,54 * *$ & - \\
\hline \hline
\end{tabular}

Note: Each line presents the correlation value $(r)$ of the combined data. All cells suggest significative correlation with $\alpha=0,01$ except: * Significative correlation with $\alpha=0,05 ; * *$ No significative correlation.

The Table 2 shows that from both perspectives the values show high variation when accessing the standard deviation and CV values. In this scenario, we can suggest that not all students were fully engaged and students present heterogeneous engagement values inside the software. However, when we performed correlations we identified that, even with heterogeneous distribution, all the variables inside 'Gamification Data' and 'Usage Data' columns expressed positive correlations (given the correlation value $[\mathrm{r}]$ presented on Table 3 ). Such values support the understanding of some characteristics related to behavioral engagement.

When we analyze the EXP element, it is evident that this variable (Earned EXP) will present positive correlation with Earned eCoins $(\mathrm{r}=0.98)$ and with Activities Attempt $(\mathrm{r}=0.85)$, given the Equation 2 and 1 respectively.

However, the outcome of positive correlation of Earned EXP with Trades Performed ( $r=0.87$ ) and Traded eCoins $(\mathrm{r}=0.85)$ was not implicit. These correlations suggest that students who holds higher EXP values make substantial use of the system and, by definition, substantial usage of gamification elements available. This result suggest that the Points element (here provided by EXP) is a positive indicator of users' engagement inside the environment. This result also agrees with several authors that suggest this advantage of using Points element given the systematic review in [14].

When we access the eCoin element, the positive correlation between this variable (Earned eCoins) and others it was also evident given the direct relationship with EXP values and activities attempt, as cited before. With trades this is also evident because users tend to spend their eCoin funds in trades when necessary. Yet, the positive correlations between Earned eCoins with Traded eCoins $(r=0.84)$ and Trades Performed ( $\mathrm{r}=0.82)$ suggest that students understand the importance of this element and use it. Still, it is noteworthy that, on average, students use $60 \%$ of their eCoin funds at the end of a given period. After all, even with the positive outcome, the eCoins could have been more explored by students.

Another important result about behavioral engagement relies on the activities attempts. Given the fact that eClass was initially designed to allow students to perform all the available activities, and the gamification elements would guide students towards a desired pedagogical sequence, the Figure 2 shows the percentage of attempts inside each difficulty over the weeks.

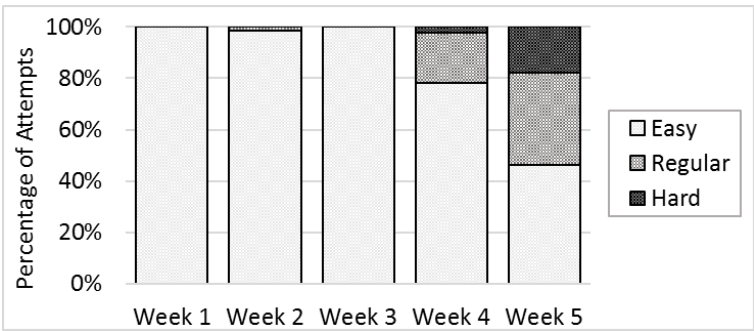

Figure 2. Percentage of activities attempts by difficulty

The Figure 2 shows that students were initially guided to perform learning activities of 'easy difficulty' (level 1) and, during the time, more attempts were made on higher difficulty levels. This suggest that students were guided to perform activities following the difficulty sequence defined by the teacher and guided by gamification elements.

To further this analysis, we can also access the percentage of attempts inside each module over the weeks (Figure 3).

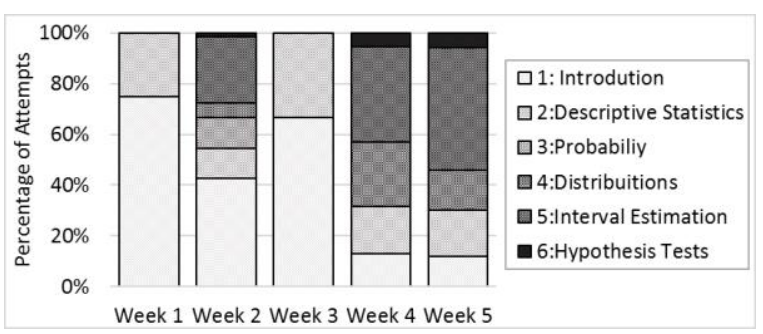

Figure 3. Percentage of activities attempts by module 
The results suggest that gamification elements successfully guided students to initially follow the teacher-designed sequence of difficulty levels and content parameters.

On the other hand, the higher levels of difficulty and contents were not fully explored by the students, suggesting that some rewards could be used to make students explore all given possibilities in future cases.

Overall, the results from a behavioral engagement perspective suggest that students did not feel homogeneously engaged in eClass usage. However, the students understand the importance of the gamification elements mostly because they follow a teacher-designed sequence and used their eCoins to perform trades. Besides, the positive correlations among the variables prove that students with higher EXP values were engaged in the eClass environment, being the EXP element a good indicator of the students' engagement.

In this sense, teachers may use EXP as a feedback element to track and guide students when performing assessments.

\subsection{Characterization of Cognitive Engagement}

The cognitive engagement was analyzed according to: students' average score; eClass final score; discipline final score. These values are presented in the 'Performance Data' column in Table 2 and Table 3.

First, we accessed the student's average score, as a mean value of the student's results of all activities performed. The correlations involving such value suggest the significant correlation with discipline final score $(\mathrm{r}=0.72)$. Some correlations (giving $\alpha=0.05$ ) also involve other variables: Earned EXP, Earned eCoins and eClass Final Score. This result suggests that, students' average result on system's learning activities reflects especially on the discipline final score. In this case, when teachers use the eClass, it is possible to track students during the attempts process and remediate them in time if the results suggest low performance levels.

On the other hand, the eClass final score (FS), presented on the system description, expresses correlation with all the data from the system except with the discipline final score $(r=0.54)$. In this scenario, to achieve higher FS values, students must perform attempts on the entire pool of required activities, given the difficulties and contents. This result suggests that students were not fully engaged to perform all required activities affecting their FS. Figure 2 and Figure 3 also corroborates with this result, proving that some difficulty levels and contents were not fully explored by the students. In such case, we suggest that future applications should instigate students to explore more activity scenarios.

Finally, the discipline final score was evaluated and compared with all the other data from the system's log. These results show that this value only present positive correlation with the students' average score $(\mathrm{r}=0.72)$, suggesting the eClass system does not directly affect the discipline final score. However, the correlation with the students' average score indicates an important issue regarding the use of eClass, proving that the students' average performance on attempts reflect on their discipline final score. As we cited before, this may be useful to teachers to track students' performance and act upon the contents that have bad results.

\section{Conclusions}

This study proposes a new learning artefact through the insertion of gamification technique inside an e-learning environment. This new approach was built to allow students to construct their own knowledge and, at the same time, involve them in learning activities. Teachers also should be benefit from this approach by the support on their daily practices regarding assessments.

After the e-learning project and development, the evaluation was made through a case-study regarding the learning of Probability and Statistics field. Then we collected data from the e-learning usage from a gamification perspective to understand their effects on the discipline course. Data were analyzed from two engagement perspectives: behavioral and cognitive.

From a behavioral engagement perspective, we conclude that not all students were engaged to perform learning activities, given the heterogeneous values of participation. However, the results prove that the students understand the gamification elements, mostly because they were guided by them to follow a teacher-designed sequence of contents and difficulty. Another important result is that the 'points' element (EXP) was significant in the behavioral engagement perspective by presenting it as an indicator of the students' engagement inside the environment. The Virtual Currency (eCoin) element also play an important role on this scenario given the students usage of them.

From a cognitive engagement perspective, we conclude that the students' average score inside learning activities is an indicator of the discipline final score, given the positive correlation among these variables. However, the correlation does not emerge from the system's final score (FS) and discipline final score. This occurs mostly because the 
FS value is directly associated with the exploration of all activity scenarios, and the students do not explore all possibilities, resulting in low FS values.

In conclusion, students using the e-learning environment were driven by gamification elements to perform learning activities and follow a teacher defined path. The results also prove that a gamified e-learning environment may affect the students' behavioral and cognitive engagement. Moreover, the e-learning environment is a powerful tool for teachers to make summative assessments and can also provide important feedback data during the development of the course.

\section{References}

[1] D. A. Norman and J. C. Spohrer, "Learner-centered Education," Commun ACM, vol. 39, no. 4, pp. 24-27, Apr. 1996.

[2] A. A. Hamid, "e-Learning: Is it the 'e' or the learning that matters?," Internet High. Educ., vol. 4, no. 3-4, pp. 311-316, 2001.

[3] T. Shopova, "E-Learning in Higher Educational Environment," Italy, 2012.

[4] S. Deterding, D. Dixon, R. Khaled, and L. Nacke, "From Game Design Elements to Gamefulness: Defining "Gamification,"' in Proceedings of the 15th International Academic MindTrek Conference: Envisioning Future Media Environments, New York, NY, USA, 2011, pp. 915.

[5] J. J. Lee and J. Hammer, "Gamification in education: what, how, Why Bother? Definitions and uses.," Exch. Organ. Behav. Teach. J., vol. 15, no. 2, pp. 1-5, 2011.

[6] D. Fernandes, "Para uma teoria da avaliação no domínio das aprendizagens," Estud. Em Aval. Educ., pp. 347-372, 2008.

[7] S. A. Ignácio, "Importância da Estatística para o Processo de Conhecimento e Tomada de Decisão," Rev. Parana. Desenvolv. - RPD, vol. 0, no. 118, pp. 175-192, Feb. 2012.

[8] C. Batanero, P. Arteaga, and J. M. Contrera, "El Currículo de Estadística en la Enseñanza Obligatoria," Rev. Educ. Matemática E Tecnológica Iberoam., vol. 2, no. 2, 2011.

[9] C. Batanero, G. Burrill, and C. Reading, Teaching Statistics in School Mathematics-Challenges for Teaching and Teacher Education: A Joint ICMI/IASE Study: The 18th ICMI Study. Springer Science \& Business Media, 2011.

[10] W. Sun and W. Zhang, "The Research of Collaborative E-learning System towards Knowledge Management," 2008, pp. 354-357.
[11] M. Prensky, "Our Brains Extended," Technol.-Rich Learn., vol. 70, no. 6, pp. 22-27, Mar. 2013.

[12] S. Deterding, R. Khaled, L. Nacke, and D. Dixon, "Gamification: Toward a definition," in CHI 2011 Gamification Workshop Proceedings, 2011, pp. 12-15.

[13] B. Shneiderman, "Designing for Fun: How Can We Design User Interfaces to Be More Fun?," interactions, vol. 11, no. 5, pp. 48-50, Sep. 2004.

[14] M. Tenório, F. Reinaldo, L. Góis, R. P. Lopes, and G. Santos Junior, "Elements of Gamification in Virtual Learning Environments: A Systematic Review," in Proceedings of the 20th International Conference on Interactive Collaborative Learning, Budapest, 2017, vol. 716.

[15] R. S. Pressman and B. Maxim, Software Engineering: A Practitioner's Approach, 8 edition. New York, NY: McGraw-Hill Education, 2014.

[16] M. M. Tenório, L. A. de Gois, and G. dos Santos Jr, "Gamification Project: A Methodology for Virtual Learning Environments," in Information Systems and Technologies - Proceedings of the 12th Iberian Conference on Information Systems and Technologies, Lisboa, Portugal, 2017, vol. 12, pp. 182-186.

[17] J. Nielsen, Usability Engineering, 1 edition. Boston: Morgan Kaufmann, 1993.

[18] M. Cipollone, C. C. Schifter, and R. A. Moffat, "Minecraft As a Creative Tool: A Case Study," Int J Game-Based Learn, vol. 4, no. 2, pp. 1-14, Apr. 2014.

[19] S. Abramovich, C. Schunn, and R. M. Higashi, "Are badges useful in education?: it depends upon the type of badge and expertise of learner," Educ. Technol. Res. Dev., vol. 61, no. 2, pp. 217-232, Mar. 2013.

[20] Y. Attali and M. Arieli-Attali, "Gamification in assessment: Do points affect test performance?," Comput. Educ., vol. 83, pp. 57-63, Apr. 2015.

\section{Acknowledgements}

The authors wish to thank the research funding agency CAPES for the scholarship granted to the post-graduate student author of this paper. 